\title{
When Is It Socially Desirable For An Individual To Comply With The Law?
}

\section{Citation}

Steven Shavell, When Is Compliance with the Law Socially Desirable?, 41 J. Legal Stud. 1 (2012).

\section{Published Version}

http://www.journals.uchicago.edu/doi/pdfplus/10.1086/664064

\section{Permanent link}

http://nrs.harvard.edu/urn-3:HUL.InstRepos:30012794

\section{Terms of Use}

This article was downloaded from Harvard University's DASH repository, and is made available under the terms and conditions applicable to Other Posted Material, as set forth at http:// nrs.harvard.edu/urn-3:HUL.InstRepos:dash.current.terms-of-use\#LAA

\section{Share Your Story}

The Harvard community has made this article openly available.

Please share how this access benefits you. Submit a story.

\section{Accessibility}




\title{
When Is Compliance with the Law Socially Desirable?
}

\author{
Steven Shavell
}

\begin{abstract}
When would an individual expect adherence to the law to advance the social good? This timehonored question is of more than intellectual interest, for if individuals have some desire to foster social welfare, the answer to it may help to explain and guide actual compliance with the law. In the model that I study, an individual's knowledge of factors relevant to social welfare is inferior to lawmakers' in some respects and superior in others. Thus, in assessing whether obeying legal rules would promote social welfare, an individual must consider that rules will impound certain superior information of lawmakers but also that rules may fail to reflect his private information. A second issue that an individual must consider in deciding whether following the law would be desirable is a compliance externality: the effect of the witnessing of his compliance behavior on the compliance behavior of observers. The conclusions from the model are interpreted, including their implications for actual compliance and for the moral obligation to obey the law.
\end{abstract}

\section{INTRODUCTION}

When does compliance with the law promote the social good? This is, of course, a fundamental question about the law and has been the subject of scholarly inquiry from the times of the earliest legal systems. ${ }^{1}$ Thus,

1. A famous example is Plato's imagined dialogue between Socrates and his friend Crito on whether Socrates should comply with Athenian law or take an opportunity to escape the punishment to which he has been sentenced (see Plato 1997). On literature concerning the duty to obey the law, see generally the references cited in notes $8,9,11$, and 12 .

STEVEN SHAVEll is the Samuel R. Rosenthal Professor of Law and Economics at Harvard Law School. I wish to thank Oren Bar-Gill, Louis Kaplow, Martha Minow, A. Mitchell Polinsky, Frederick Schauer, Scott Shapiro, M. B. E. Smith, and Adrian Vermeule for comments and James McGinnis, Monica Mleczko, and David Simon for research assistance.

[Journal of Legal Studies, vol. 41 (January 2012)]

(C) 2012 by The University of Chicago. All rights reserved. 0047-2530/2012/4101-0001\$10.00 
a writer must approach the topic of the social desirability of adherence to the law with some reserve. I address the topic nevertheless because I believe that an examination of it through a modern analytical lens will prove clarifying. In particular, I will take explicit account of the often different information that individuals and the state possess about the social desirability of acts governed by legal rules and also of the specific channels through which individuals' compliance behavior may influence observers of that behavior.

It should be emphasized that the topic at issue is of relevance for economically oriented analysts of law, who seek to predict and explain compliance with the law on the basis of individual rationality. The general reason is that individuals seem to care to some degree about the well-being of others, ${ }^{2}$ and I will broadly construe this concern as social welfare. If, then, an individual derives positive utility from social welfare, his decision of whether to comply with a law will be influenced by whether his compliance would promote social welfare. His compliance decision will also obviously be affected by, and will often be dominated by, conventional utilitarian considerations, namely, the personal benefits he would derive from disobedience and the sanctions he might suffer as a result. My purpose here, however, is not to examine how these standard utilitarian factors combine with the factor of social welfare in an individual's compliance decision. Rather, it is to focus on social welfare as a determinant of the compliance decision; in other words, my goal is to study one ingredient of the compliance decision. We must know the answer to the question, what would a person rationally believe to be the effect of his compliance with the law on social welfare, in order to ascertain how consideration of social welfare would enter into the person's calculus of compliance. ${ }^{3}$

2. The hypothesis that individuals behave in part to advance the interests of others, not just their narrowly personal wants, has been developed by many scholars, including philosophers such as Hume ([1751] 1957) and Smith ([1790] 1976) and in recent years by economists including Elster (1998), Frank (1988), Kaplow and Shavell (2007), and Rabin (1993). The hypothesis has also been supported by natural scientists who argue that our moral capacities are to some degree the product of natural selection because these capacities furnish humans with a desire to behave in unselfish and broadly beneficial ways (see Darwin [1874] 1998, chap. 5; see also Haidt 2003; Hauser 2006; Pinker 1997).

3 . The question investigated in this article, concerning an individual's rational assessment of the effect of compliance with legal rules on social welfare, has not been addressed before in the economic literature on law to my knowledge. However, the present article is related to the literature on social and ethical norms and compliance in the sense that that writing also considers factors going beyond the standard utilitarian ones (see, for example, McAdams 1997; Posner 1996; Posner 1997; Shavell 2002). 
The article is organized as follows. In Section 2, I employ a stylized model to investigate the direct effects of obeying the law ${ }^{4}$ on social wellbeing. ${ }^{5}$ The effects of compliance with the law depend on its design, and I assume that the goal of lawmakers in fashioning the law is to enhance social welfare. I, therefore, suppose that lawmakers generally consider a great deal of information relevant to social welfare in formulating legal rules.

However, I also suppose that lawmakers are unable to incorporate a variety of circumstantial factors relevant to social welfare into legal rules. A legal rule governing the use of pesticides, for example, might not reflect the value of the plants that a particular person would wish to protect with a pesticide or local wind conditions that could influence the risk to others of exposure to the pesticide. A justification for this assumption that laws are inevitably incomplete in the considerations that they recognize is the difficulty or impracticality that courts would face in observing or verifying many circumstantial factors. ${ }^{6}$

The central issue that I address is whether from an individual's perspective-which is to say, given the knowledge that an individual possesses-an action taken in compliance with the law would be expected to raise social welfare. It is the individual's vantage point that must be adopted if one wishes to ascertain how an individual could behave to foster social welfare, for an individual is able to act on, and only on, the basis of what he knows.

I assume that individuals understand that lawmakers craft the law to promote social welfare but that individuals do not possess, and realize that they do not possess, some of the information on which legal rules are premised, such as that from scientific literature on the dangers of pesticide use. At the same time, I suppose that individuals are aware of the circumstantial factors bearing on social welfare that the state does not take into explicit account in legal rules (the value of the plants that would be protected by a pesticide or local wind conditions).

Hence, two key features of the model shape an individual's evaluation

4. By the direct effects of obeying the law, I refer to the consequences of acts of compliance or of noncompliance themselves; that is, I exclude any effects of the witnessing of compliance behavior on observers' tendency to obey the law.

5. I use the terms "social well-being," "social welfare," and the "social good" synonymously, and I assume that the concept of the social good is shared by individuals so that I can abstract from issues concerning failure to comply with the law rooted in disagreement about the underlying social objectives of the law.

6. I discuss another justification in Section 2.3. 
of the social desirability of compliance with the law: that lawmakers, who devise legal rules to advance social welfare, make use of information that is in some respects superior to individuals'; and that individuals possess information that is relevant to social welfare but that is not reflected in legal rules.

The main conclusions that I reach in Section 2 are readily summarized. On one hand, individuals will often come to the belief that complying with the law would be socially desirable. It will frequently be obvious to an individual that complying with the law would be socially good because a proscribed act would plainly be harmful or excessively dangerous (driving at 70 miles per hour in a school zone) in relation to the benefit the individual would derive from committing the act. In many cases, though, it will not be evident to individuals from their personal knowledge that obeying the law would be socially advantageous. Yet in such cases, an individual might still rationally infer from the illegal status of an act that it would be socially undesirable, for its status impounds information that the individual does not possess but will appreciate has contributed to the decision of the state to classify the act as illegal. Thus, an individual might infer that application of a pesticide would be undesirable from the fact that use of the pesticide is legally prohibited; this prohibition could signal that the pesticide is carcinogenic or has some other dangerous property of which the individual does not have direct knowledge. As I will discuss, such inference from the legal status of an act implies that an individual's view of the social desirability of an act will frequently be determined by its legality.

On the other hand, individuals will sometimes conclude that complying with the law would be socially undesirable. Circumstantial factors that are not reflected in the law may indicate that obeying the law would not be socially advantageous (suppose that the plants that could be protected by a prohibited pesticide are especially valuable or that there is no wind when the pesticide would be applied, meaning that the risk of pesticide exposure to neighbors would be negligible). In these cases, an individual may find that the benefit that he would obtain from an illegal act outweighs its estimated harmfulness, including through inference from its illegality, and this assessment would imply that violating the law would be socially good.

I then discuss these conclusions from the model in relation to several examples-regarding fire protection codes, traffic regulations, tax rules, and criminal law. I also comment on the interpretation of the analysis, including the importance of the inferences individuals can rationally 
make from the law and the likelihood that disobeying the law would be socially desirable. I suggest that although obeying the law would tend to be judged socially desirable by individuals, situations in which disobeying the law would be socially beneficial will not be unusual in many domains because of the significance of factors not incorporated into the law.

I comment as well on the connection between the analysis and the obligation to obey the law under social contractarian ideas, the obligation to obey under an influential view based on the expertise of lawmakers, ${ }^{7}$ and, among other things, the desirability of employing modest sanctions for noncompliance with the law in implicit recognition of the possibility that noncompliance is desirable.

In Section 3, I turn to a different, indirect effect of compliance with the law on social welfare, an effect that I will refer to as the compliance externality. Namely, when the compliance behavior of an individual is witnessed by other parties, their tendency to conform to the law may be influenced, and, thus, social welfare may be affected. As an initial matter, I note that the compliance externality is of potential relevance only when compliance behavior is observed, such as when a driver goes through a red light in traffic; often, however, compliance behavior goes unnoticed, such as would usually be true when a person cheats on his income tax return.

Assuming that compliance behavior would be observed by others, I investigate the manner in which their proclivity to comply with the law could be altered. One possible avenue of influence on observers is the morally tutelary-that the witnessing of compliance behavior would in some fashion effect a change in the desire of observers to foster the social good and, thus, to obey the law. Another channel of influence on observers is through their inferences about the likelihood or magnitude of legal sanctions. If a person were to learn that a financially knowledgeable individual made an illegitimate deduction on his income tax return, the person might infer that the audit probability for that deduction is low. A third form of influence on observers is through their inferences about social sanctions for violations of the law. As I will explain, it is possible that witnessing violations of the law will lead rational observers to believe that they will be less likely to face social disapproval for disobeying the law than they had previously thought. A complication that bears on all three channels of influence on observers is the importance of the

7. This is the view developed by $\operatorname{Raz}$ (1986, chap. 3). 
knowledge that observers have of the circumstances surrounding witnessed compliance behavior. If, for instance, a driver is observed speeding and his purpose is to reach a hospital on account of a medical emergency, the effect on observers will depend on whether they know that purpose.

In light of the analysis in Sections 2 and 3, an individual can in principle ascertain whether obeying the law would or would not be expected to enhance social welfare by considering both the direct effect and the indirect, external effect on observers of compliance behavior. How does this bear on whether individuals will comply with the law? I address this question in Section 4.

Before proceeding, let me state how the present article relates generally to prior literature on the duty to obey the law. ${ }^{8}$ The dominant concern of that literature has been with the question whether and, if so, why individuals should feel a duty to obey the law. ${ }^{9}$ The chief object of this article, however, is not to examine whether individuals have a duty to obey the law under one or another theory of moral obligation. Rather, it is to ask when it would be desirable on consequentialist grounds for individuals to adhere to the law. ${ }^{10}$ It might be thought that utilitarian writers would have addressed that question, but Bentham and other prominent consequentialists have taken it largely for granted that compliance with the law sometimes is and sometimes is not desirable without elaborating the conditions under which one or the other outcome would be expected to hold. ${ }^{11}$ The literature that is most closely related to this

8. For an evaluation and survey of this literature, see Simmons (1979).

9. Perhaps the most widely known answer that scholars have developed is that a social contract may exist, or may be imputed, and such a contract engenders a broad obligation of compliance with legal rules. Classic formulations of the theory of the social contract are presented by Hobbes ([1651] 2008), Locke ([1689] 1988), and Rousseau ([1762] 1968); a powerful criticism of the theory is offered by Hume ([1748] 1978). Other justifications for a duty to obey the law include the principle of fair play, initially developed by Hart (1955) and Rawls (1964), and gratitude for the benefits of government, on which see, for example, Simmons (1979, chap. 7). Since the 1970s, much of the scholarly writing on the duty to obey the law (on which see note 12) has discussed reasons for skepticism about the claim that there exists a duty that is essentially independent of the content of the law.

10. That the question I ask in Sections 2 and 3 is different from the question of whether individuals have a moral obligation to obey the law should be clear: whether an individual for whom the consequences of compliance with the law would raise social welfare would also have a duty to obey the law depends on the notion of moral obligation (deontic, welfaristic, religious, or some other).

11. Notably, the statements of Bentham ([1776] 1988) about compliance with the law are so general that they are unhelpful; in section 43 of chapter 1 , for example, he observed that individuals should obey the law as long as "the probable mischiefs of obedience are less than the probable mischiefs of resistance." Other important utilitarians, including 
article investigates whether there exist prima facie obligations to obey the law, which is to say, whether there exist distinctive, mainly nonconsequentialist, arguments favoring compliance. ${ }^{12}$ Writers on this topic consider consequentialist grounds for obeying the law in the course of inquiring whether there are additional grounds for compliance. Although these writers identify important consequentialist reasons for compliance, they do not develop them in a sustained way and pay relatively little attention to the functioning of the compliance externality. ${ }^{13}$

\section{THE DIRECT EFFECT OF COMPLIANCE WITH THE LAW ON SOCIAL WELFARE}

\subsection{A Stylized Model}

I will begin by setting out a stylized model of acts that individuals might commit, the knowledge of individuals and of the state, the determination of the law, and social welfare. If an individual commits an act, the individual will enjoy a personal benefit and may cause harm to others. Social welfare is taken to be utilitarian: the sum of the benefits that the population of individuals derive from the acts that they commit minus the harms that the acts engender. ${ }^{14}$ Consequently, it will be socially best for an act to be committed if the benefit flowing from the act exceeds the harm caused by the act and socially best for the act not be committed if the harm outweighs the benefit. ${ }^{15}$

The object of the analysis in this section is to ascertain only whether an individual would rationally judge that compliance with the law would raise social welfare. This is hardly to say that an individual would obey the law if he believed that doing so would raise social welfare. Often

J. S. Mill and H. Sidgwick, said little or nothing about the obligation to obey the law (see the discussion of early utilitarians on the duty to obey the law in Simmons 1979, pp. 4649).

12. Key writing on the prima facie obligation to obey the law includes Smith (1973) and $\operatorname{Raz}(1979,1986)$; see also the symposium on the writings of Raz in the Southern California Law Review (1989), the collection of contributions in Edmundson (1999), Schauer (1991), and the reviews of Shapiro (2002) and Smith (2010).

13. Lest I be misunderstood, let me say that the observation that these writers do not amplify the consequentialist reasons for compliance with the law is not meant as a criticism, for their chief purpose has not been to analyze these reasons but instead to examine whether other reasons for compliance with the law can be adduced.

14. This assumption is made for expository convenience; the qualitative conclusions that will be reached would be the same if social welfare were a different function of the utilities of individuals.

15. If the harm equals the benefit, it will not matter to social welfare whether the act is committed, and I will generally omit discussion of this case in the rest of the article for simplicity. 
he would not, for I assume that the factor of social welfare is only one component of a person's utility, ${ }^{16}$ and, hence, that the selfish benefits he would obtain from disobedience might outweigh the factor of social welfare and that of possible legal sanctions.

\subsubsection{The Determination of the Law in Light of the Information Possessed}

by the State. I assume that the objective of the state in fashioning the law is to maximize social welfare. ${ }^{17}$ In the ideal, then, the state would declare an act to be permissible if the benefit an individual would derive from it exceeds the harm the act would cause, and the state would otherwise declare an act to be a violation of the law. ${ }^{18}$

However, I also suppose that the state cannot design the law perfectly because the state is generally unable to obtain complete information about the benefits and harms from acts. In the example of the pesticide, as I mentioned, the state might not be able to determine the benefit an individual would obtain from use of the pesticide, say, because the value of the plants at risk is idiosyncratic or the state might not be able to ascertain the harm from the pesticide because of lack of knowledge of wind conditions at the time of its application. If the state cannot obtain information about such variables, it cannot apply a law that depends on these variables, so it will not incorporate them explicitly into the law.

Although the assumption that the state lacks information about var-

16. For clarity, I should be explicit about the definitions of individual utility and social welfare to which I refer in this article, especially because it might be thought that there is a circularity in the definition of social welfare that I have in mind: namely, social welfare is supposed to a function of the utilities of individuals, but I am assuming that the utility of each individual depends on social welfare. Under the following definitions, there is no problem of circularity. Let $u_{i}$ be called the conventional utility of individual $i$, by which I mean the utility derived from all conceivable sources of utility other than a source that I am about to define. Let $s=f\left(u_{1}, \ldots, u_{n}\right)$ be called conventional social welfare, that is, a function of the conventional utilities of the population of $n$ individuals. Let $U_{i}=g_{i}\left(u_{i}, s\right)$ be called the morally inclusive utility of individual $i$, derived both from conventional sources of utility and from conventional social welfare. Let $S=F\left(U_{1}, \ldots, U_{n}\right)$ be called morally inclusive social welfare. (Some such $S$ must be treated as social welfare under the usual assumptions of welfare economics, as $S$ must be a function of the utilities of individuals, and thus of the $U_{i}$.) Finally, note that the definition of $S$ is not circular, for what individual utilities are assumed to depend on is $s$, not $S$.

17. This assumption is made for simplicity, and especially because my goal is to examine why compliance with the law would or would not promote social welfare. If the law were designed to promote a nonwelfarist objective, then I would face the complicating (but banal) possibility that compliance with the law would not advance social welfare because the purpose of the law conflicts with social welfare.

18. The reader should interpret violations of the law generally to include both criminal and civil violations (such as negligent acts). 
iables bearing on benefits or harm is the one I make in the model to explain the less than ideal nature of legal rules, another reason for the imperfection of legal rules exists. Namely, it is impractically costly for lawmakers to articulate legal rules beyond a certain level of detail. I will discuss this reason for the imperfection of legal rules in Section 2.3 below, when I interpret the model.

To continue, the specific assumption that I make about the state's information about benefits is that it does not know the particular benefit, $B$, that an individual would derive from an act, but the state does know the probability distribution of benefits across the relevant population of individuals ${ }^{19}$ who might commit the act. ${ }^{20}$

I suppose that the total harm caused by an act consists of a general component, $H_{\mathrm{s}}$, that the state ascertains and also of a circumstantial component, $H_{\mathrm{C}}$, that the state does not know. In the pesticide example, the state might use medical, epidemiological, and other scientific information to determine the general component of harm, as I suggested, whereas the state might not be able to determine the circumstantial component of harm because it lacks information about wind conditions, the local topography, the proximity of neighbors, and the like. Although the state does not know $H_{\mathrm{C}}$, I presume that the state knows its probability distribution. ${ }^{21}$

Because the state has only imperfect knowledge of the benefit and of the harm from an act, the state cannot determine the legal status of an act in the ideal manner, by comparing the actual benefit to the actual harm. The best that the state can do is to compare the expected benefit of an act to the expected harm. Thus, the state will categorize an act as legally permissible if the expected benefit exceeds the expected harm,

19. The reader may wish to interpret the relevant population as individuals of a particular type, such as the population of homeowners.

20. That the state knows the probability distribution of $B$ is in keeping with the standard characterization of knowledge in formal economic models. It is generally presumed that actors (here, one actor is the state) know the structure of the model, including the probability distributions of variables. The motivation is that in the long run, actors would learn the general structure of the world that they inhabit.

21. To amplify, I suppose for simplicity that the distributions of $H_{\mathrm{C}}$ and $B$ are independent of $H_{\mathrm{s}}$. It may be helpful, however, to describe the most general model of the type that I consider in the text. In such a model, there are underlying states of the world, $\theta$, with a distribution $F(\theta)$, where a state of the world is a complete description of the world. Thus, $\theta$ determines the variables $B(\theta), H_{\mathrm{C}}(\theta)$, and $H_{\mathrm{S}}(\theta)$. The distributions of $B$ and of $H_{\mathrm{C}}$ could be correlated with $H_{\mathrm{s}}$ rather than, as I presume, independent of $H_{\mathrm{s}}$. For my purposes, examining the general model rather than the version of it that I consider in the text would be distracting. 
and it will deem an act to be legally impermissible if the expected harm exceeds the expected benefit. In terms of our notation, the law may therefore be described as follows: an act will be legally permissible if $E(B)$ exceeds $H_{\mathrm{S}}+E\left(H_{\mathrm{C}}\right)$, whereas an act will be legally prohibited if $H_{\mathrm{S}}+E\left(H_{\mathrm{C}}\right)$ exceeds $E(B) .^{22}$ (Here $E$ stands for expected value.)

To illustrate with a numerical example, suppose that the benefit, $B$, from use of a pesticide varies among different owners between 0 and 300 and that $B$ is uniformly distributed in this interval of values. Thus, the expected benefit, $E(B)$, is $150 .^{23}$ Suppose too that the component of harm, $H_{\mathrm{S}}$, known to the state owing to its expertise is 125 . Assume also that the circumstantial component of harm, $H_{\mathrm{C}}$, ranges between 0 and 100 and is uniformly distributed, so that its expected value, $E(H)$, is 50 . Consequently, the total expected harm from use of the pesticide is $125+50$, or 175 , which exceeds the expected benefit of 150 . Hence, the state would declare use of the pesticide to be illegal.

2.1.2. The Information of Individuals. Let me now turn to what individuals know and do not know. An individual is presumed to understand the benefit, $B$, that he would derive from an act. For instance, an individual would naturally know the value of his plants. I assume as well that the individual knows the distribution of $B$ in the population.

Individuals also have knowledge of the circumstantial component of harm, $H_{\mathrm{C}}$, that an act would cause. The motivation for this assumption is that individuals often observe aspects of their particular situation that the state does not, such as whether it is windy when a pesticide is applied or whether there are individuals nearby who would be likely to be exposed to it. I assume too that the individual knows the distribution of $H_{\mathrm{C}}$.

22. Although it is natural to assume that the law is determined as described in this paragraph, such a law might be termed only naively optimal because it does not reflect a number of factors bearing on social welfare. A principal omitted factor is enforcement costs. Thus, it might be desirable to permit an act that creates greater expected harm than expected benefits in order to avoid the costs of enforcing a law against it. Another omitted factor is the very fact that individuals will draw inferences from the legal status of acts. For us to consider a more sophisticated definition of optimal law would, however, be a needless complication, for the qualitative nature of the conclusions to be reached would not be altered by doing so. These conclusions will be seen to depend primarily on the assumption that individuals know how the state determines the law (not on whether the law is optimal in a refined sense) and on the assumption that individuals have knowledge relevant to social welfare that the state does not possess.

23. That is, since the benefit is equally likely to be anywhere in the interval from 0 to 300 , the expected benefit is 150 . 
However, I suppose that individuals do not know the value of the state-ascertained component of harm, $H_{\mathrm{s}}$, because they lack the knowledge or sufficient incentive to acquire this information. ${ }^{24}$ An individual is assumed to know, however, the distribution of $H_{\mathrm{S}}$ across acts, such as the use of different pesticides.

In the numerical example, let us suppose that $H_{\mathrm{S}}$ is uniformly distributed between 50 and 350 over the population of acts. Thus, even though the state knows that the true $H_{\mathrm{S}}$ is 125 for the pesticide in question, the individual does not possess this information; all that the individual initially knows is that $H_{\mathrm{S}}$ is some number between 50 and 350.

Finally, I assume that individuals understand the law-which acts are legal and which are illegal-and how the state determines the law, namely, that the state endeavors to maximize social welfare given its knowledge.

\subsubsection{The Rational Inference of Individuals about the Harmfulness of Acts}

from Their Legal Status. If an act has been made illegal by the state, intuition suggests that an individual can make a rational inference that the component of harm known to the state, $H_{\mathrm{s}}$, must have been relatively high, for otherwise the state would have permitted the act. This inference can be described in specific terms as follows. An individual knows that the state must have been led to give the act its illegal status by a determination that the expected harm from the act, $H_{\mathrm{S}}+E\left(H_{\mathrm{C}}\right)$, exceeds the expected benefit, $E(B)$, and this conclusion implies that $H_{\mathrm{S}}$ exceeds $E(B)-E\left(H_{\mathrm{C}}\right)$. Let the expected value of $H_{\mathrm{S}}$ given that it exceeds $E(B)-E\left(H_{\mathrm{C}}\right)$ be denoted $E\left(H_{\mathrm{S}}^{+}\right)$. The term $E\left(H_{\mathrm{S}}^{+}\right)$is larger than $E\left(H_{\mathrm{S}}\right)$ since the latter is the expected value of all $H_{\mathrm{s}}$, not just the $H_{\mathrm{S}}$ that exceed $E(B)-E\left(H_{C}\right)$.

In the numerical example, if use of the pesticide is illegal, an individual knows that $H_{\mathrm{S}}+E\left(H_{\mathrm{C}}\right)$ must exceed $E(B)$, or that $H_{\mathrm{S}}+50$ must exceed 150 . Hence, the individual knows that $H_{\mathrm{S}}$ exceeds 100 , but the individual does not know what $H_{\mathrm{S}}$ really is and, thus, how dangerous

24. The state might want to communicate $H_{\mathrm{S}}$ to individuals because it seeks to maximize social welfare. (It will be apparent that social welfare would be advanced if individuals know $H_{\mathrm{s}}$ and one of their objectives is to raise social welfare.) Thus, the assumption that individuals do not know $H_{\mathrm{s}}$ depends implicitly on the assumption that the state cannot easily communicate it. This assumption would hold if effective description of $H_{\mathrm{S}}$ to individuals requires that they have scientific or other technical knowledge that they are unlikely to possess. 
the pesticide really is. Because $H_{\mathrm{S}}$ is uniformly distributed between 50 and 350 and the pesticide is illegal, the individual infers that $H_{\mathrm{S}}$ is somewhere between 100 and 350 and, hence, that its expected value, $E\left(H_{\mathrm{S}}^{+}\right)$, must be 225 .

An individual can draw an analogous conclusion if an act is classified by the state as permissible. In this case, an individual can deduce that the harm the act causes is relatively low and, in particular, that $H_{\mathrm{S}}$ must be below $E(B)-E\left(H_{\mathrm{C}}\right)$. In the example, if use of the pesticide were legal, an individual would infer that $H_{\mathrm{s}}$ must be less than 100, which is to say, somewhere between 50 and 100 . This in turn would mean that the expected value of $H_{\mathrm{s}}$ would be only 75 . Hence, $225-75$, or 150 , is the difference in expected harm that an individual would infer from knowledge that the pesticide is illegal rather than legal.

Notice from this example that the power of the inference that is drawn from the legal status of an act can be significant because it depends on the swing in the conditional expected value of harm when an act is illegal from when it is legal. It is not just that the individual infers higher harmfulness than the average harmfulness from the fact that an act is illegal; it is also that the individual would infer lower harmfulness from the fact that an act is legal. ${ }^{25}$

However, the importance of inference from the legal status of acts also depends on individuals' initial uncertainty about the harmfulness of acts, which is to say, on the dispersion of the distribution of $H_{\mathrm{s}}$. A widely dispersed distribution corresponds to individuals having little direct knowledge of the true $H_{\mathrm{s}}$, and this broad distribution implies that inference from the legal status of acts would be important. A concentrated distribution of $H_{\mathrm{S}}$ corresponds to individuals having fairly accurate knowledge of $H_{\mathrm{S}}$, meaning that inference from the legal status of acts might not be significant. Indeed, if the entire probability mass of $H_{\mathrm{S}}$ were focused at a single point-if individuals knew $H_{\mathrm{s}}$ for sure-the legal status of an act would have no bearing on an individual's evaluation of its harmfulness.

25. To be precise, if an act is legal, it must be that $H_{\mathrm{S}}$ falls below $E(B)-E\left(H_{\mathrm{C}}\right)$. If the expected value of $H_{\mathrm{S}}$ in this region is denoted by $E\left(H_{\mathrm{S}}^{-}\right)$, then we can say that the individual knows that the expected harm from a legal act is $H_{\mathrm{C}}+E\left(H_{\mathrm{S}}^{-}\right)$. Because the expected harm from an otherwise identical act that is illegal is $H_{\mathrm{C}}+E\left(H_{\mathrm{S}}^{+}\right)$, the difference in expected harm due to illegality is $E\left(H_{\mathrm{S}}^{+}\right)-E\left(H_{\mathrm{S}}^{-}\right)$. Hence, if the individual's benefit, $B$, is between $H_{\mathrm{C}}+E\left(H_{\mathrm{S}}^{-}\right)$and $H_{\mathrm{C}}+E\left(H_{\mathrm{S}}^{+}\right)$, then the individual would judge the act to be socially desirable if it is legal and yet to be socially undesirable if it is illegal. 


\subsubsection{When Will Compliance with the Law Promote Social Welfare Given the Information Possessed by Individuals and Given Their Rational Inferences} from the Legal Status of Acts? Now we can answer the central question of this section: How can a person decide whether complying with the law would raise expected social welfare ${ }^{26}$ To do this, a person has to compare the benefit from an illegal act with the harm from the act, given his knowledge, both direct and inferential. The individual knows the benefit, $B$, and the circumstantial component of harm, $H_{\mathrm{C}}$. The individual also infers from the illegality of the act that the other component of harm is $E\left(H_{\mathrm{S}}^{+}\right)$. Hence, the individual compares $B$ to $H_{\mathrm{C}}+E\left(H_{\mathrm{S}}^{+}\right)$and determines that compliance would raise social welfare if $H_{\mathrm{C}}+E\left(H_{\mathrm{S}}^{+}\right)$ exceeds $B$, whereas noncompliance would raise social welfare if $B$ exceeds $H_{\mathrm{C}}+E\left(H_{\mathrm{S}}^{+}\right)$.

In the numerical example, suppose that the individual's benefit, $B$, is 200 and that the circumstantial component of harm, $H_{\mathrm{C}}$, is 20 . We know that if use of the pesticide is illegal, $E\left(H_{\mathrm{S}}^{+}\right)$must be 225 . Hence, the total expected harm would be $20+225$, or 245 , exceeding the benefit of 200 , so that compliance with the law would be socially best. If, however, the individual's benefit were 275 , the individual would calculate that noncompliance would raise social welfare. We can also determine the likelihood that an individual would decide that noncompliance is best. This will be true when the benefit, $B$, exceeds $H_{\mathrm{C}}+225$ or when $B-H_{\mathrm{C}}$ exceeds 225 . The probability of this occurring can be shown to be 9.375 percent ${ }^{27}$ and, thus, the probability of a person finding that compliance with the law is socially best is 90.675 percent. $^{28}$

26. However, the reader should bear in mind that in this section I omit consideration of the effect on social welfare of the witnessing of compliance behavior.

27. It is evident the probability that $B-H_{\mathrm{C}}>225$ rises linearly from 0 at $B=225$ to .75 at $B=300$ (for $300-H_{\mathrm{C}}>225$ will hold if $H_{\mathrm{C}}<75$ ). Hence, the average probability that $B-H_{\mathrm{C}}>225$ holds when $B$ is between 225 and 300 is (.75/2). Since the probability that $B$ is in $[225,300]$ is .25 , the probability in question is $(.25)(.75 / 2)=.09375$.

28. The determination of when it is desirable to comply with the law to this point in the analysis may be regarded as an elaboration and a formalization of two types of observation frequently made in modern philosophical literature on the duty to obey the law (and doubtlessly in earlier work as well). First, writers in this literature usually mention simple examples in which disobeying the law would not be undesirable on consequentialist grounds (see, for instance, Smith 1973, p. 971), such as going through a red light when there is no traffic. (These examples implicitly rely on the fact that the law does not incorporate certain factors relevant to social welfare of which individuals will have knowledge.) Second, they often note that individuals should take into account that the law may reflect considerations bearing on social welfare about which the state has superior information. See, for example, Smith (1973, p. 975); Raz (1999, pp. 165-67). See also Alexander and Sherwin (2001, chap. 4) and the discussion of Raz in Section 2.3. 


\subsubsection{Social Welfare Will Be Higher on Average If Individuals Disobey the Law whenever They Believe That Noncompliance Would Raise Social Welfare.} It follows from what has been said that expected social welfare will be fostered if individuals disobey the law when and only when they determine in the manner that I have described that noncompliance would promote social welfare. ${ }^{29}$ Of course, when an individual decides that noncompliance is best, compliance could turn out to be best in that specific instance because the true magnitude of the component of harm, $H_{\mathrm{s}}$, that the individual does not observe might be relatively high. This possibility is not paradoxical; the point is that when an individual ascertains that noncompliance is best, it will be desirable not to comply only on average. The foregoing observation can be better appreciated by further examining our example. We know that individuals judge that noncompliance is best when $B-H_{\mathrm{C}}$ exceeds 225 and, thus, for instance, if $B-H_{\mathrm{C}}$ is 250 . In this case, despite the beliefs of individuals, compliance would in fact be socially desirable when $H_{\mathrm{S}}$ exceeds 250 , an event with a probability of 40 percent. $^{30}$ If $B-H_{\mathrm{C}}$ is higher, say 300 , compliance would in fact be desirable when $H_{\mathrm{S}}$ exceeds 300 , an event with a probability of only 25 percent. ${ }^{31}$ In other words, the more that $B-$ $H_{\mathrm{C}}$ exceeds 225 , the lower is the likelihood that compliance would turn out to be best. In any event, in all cases where $B-H_{\mathrm{C}}$ exceeds 225 , social welfare rises on average if individuals do not comply with the law.

\subsubsection{The Possible Social Undesirability of Committing Legally Permissible}

Acts. It is worth observing that an individual can also calculate the social welfare consequences of committing acts that are permissible and that an individual may conclude that committing such an act would lower expected social welfare. Specifically, I noted above that if an act is permissible, an individual will infer that the unobserved component of harm, $H_{\mathrm{S}}$, falls below $E(B)-E\left(H_{\mathrm{C}}\right)$, in which case its expected value is $E\left(H_{\mathrm{S}}^{-}\right)$. Accordingly, the individual will judge the expected harm from

29. This claim is in its essence trivial: an individual's decision whether to comply with a legal rule can depend on, and only on, the information that the individual possesses. I have explained when compliance would raise expected social welfare given the information that the individual possesses. Hence, if individuals obey the law exactly under the conditions that I have said would raise expected social welfare, they will be acting to maximize expected social welfare given the information that they possess.

30. Because the act is presumed to be illegal, individuals know that $H_{\mathrm{S}}$ must be at least 100 , and so must be in the interval [100, 350]. Given that $H_{\mathrm{S}}$ lies in this interval, the probability that $H_{\mathrm{S}}$ exceeds 250 is $100 / 250$, or 40 percent.

31. By the logic of the previous note, the probability in question is $50 / 250$, or 25 percent. 
the act to be $H_{\mathrm{C}}+E\left(H_{\mathrm{S}}^{-}\right)$and will reason that the act would lower social welfare if his benefit, $B$, falls below this amount. In our example, if the pesticide is permissible, the individual will know that $H_{\mathrm{S}}$ must be below 100 , and this result implies that its expected value, $E\left(H_{\mathrm{S}}^{-}\right)$, is 75 . Hence, if, say, $H_{\mathrm{C}}$ were 50 , making the expected harm 125 , the individual would judge its use socially undesirable whenever his benefit was below 125 .

\subsection{Examples}

Let me now discuss several examples to illustrate the analysis.

2.2.1. Fire Safety Regulation. There are many requirements that must be met to satisfy fire safety regulations concerning, for example, smoke alarms, fire escapes, exit signs, sprinkler systems, electrical wiring, and the use of fire retardant materials. I surmise that individuals will usually come to the judgment that failure to comply with these requirements could create substantial dangers and, thus, would be viewed by them as socially undesirable. In particular, individuals assume that the regulations reflect consideration by lawmakers of a large body of knowledge bearing on the control and amelioration of fire risks, as embodied in scientific studies, fire safety recommendations of expert groups, and the like. The average person does not possess much of this knowledge himself but does appreciate that fire safety regulations are designed in light of it. Hence, if a homeowner knows that his smoke alarm system satisfies the fire safety code, the homeowner will presumably believe that the smoke alarm system will function tolerably well, whereas if a smoke alarm system with outwardly similar characteristics does not meet the code, the homeowner would probably evaluate the system in a meaningfully different way. In other words, the legal requirements concerning fire safety implicitly contain significant information for regulated parties about their social desirability, information that should tend to lead parties rationally to conclude that compliance with the requirements would be socially desirable. At the same time, some fire safety requirements have an obvious rationale to individuals, so that the legal status of these requirements impounds little information about the dangers they avert. For example, a requirement that exits from a room not be locked or a rule that gasoline not be stored near a furnace would fit in this category.

Although individuals will usually believe that obeying fire safety requirements will enhance social welfare, it is evident that there will be occasions in which a person will find that not following fire safety rules would be socially best. Suppose that the fire safety rules mandate that 
a smoke alarm be installed in every bedroom of a home. Suppose further that a homeowner does not have a smoke alarm in one bedroom, but that this room is used as a study and there is an alarm just outside the room in the hallway. Then the homeowner could well reasonably conclude that the benefit of having a smoke alarm in the bedroom would be negligible and outweighed by the cost and, hence, that adhering to the code requirement would not be socially desirable. ${ }^{32}$ Such situations, in which the circumstantial information of a homeowner is not taken into explicit account in fire safety regulations and indicates that following the regulations would not be socially desirable, are easy to envision, even though they would not be typical.

2.2.2. Traffic Safety Rules. Our driving behavior is governed by a variety of familiar rules, namely, those relating to stop signs, traffic lights, speed limits, the use of turn signals, and so forth. Again, it seems that individuals will generally regard adherence to these rules as promoting the social good, for the rules are understood to be designed to reduce accident dangers and to foster and coordinate traffic flow. ${ }^{33}$ Realizing that these objectives underlie traffic rules and that they reflect the expertise of lawmakers, individuals should often make useful inferences about the problems that would be created by disobedience. Consider a driver who approaches a stop sign. The driver will presumably usually judge that the chance of an accident were he to proceed through the intersection at normal speed would be relatively high-for usually there will not be a stop sign on the crossing road. Moreover, the driver will understand that stop signs coordinate traffic because it will tend to flow better through an intersection if it is unimpeded along one road and must stop on the other road than if there were no stop signs on either crossing road. Consequently, the placement of stop signs carries real information to individuals about risks and coordination benefits that should lead to the view that obeying stop signs is usually socially desirable. Of course, in many situations the information conveyed by the

32. This example (and some others that I will discuss) is not literally described by the model I examined in Section 2.1 (because it is not assumed in the example that the state observes one component of harm and the individual another additive component). But the general qualitative points made in the model apply.

33. Benefits of coordination are not described by the model in Section 2.1, but it would be easy to modify the model to accommodate such benefits, with no change in the qualitative conclusions (individuals would not know the magnitude of these benefits and so would have to make an inference about them, and individuals would make use of this inference and their knowledge of $H_{\mathrm{C}}$ and $B$ much as in the model). 
fact that a traffic rule exists will be relatively unimportant to a person's evaluation of the behavior commanded by the rule because the person's direct knowledge will itself lead him to believe that compliance would be best. This might well be the case of a low speed limit in a school zone, where it would probably be evident that there is a substantial risk to children.

However, to say that obeying traffic rules would usually be regarded by individuals as socially best almost immediately invites the response that circumstances may arise in which violating these rules would not be seen as undesirable. A driver might decide that going through a stop sign would not be socially bad if the driver can see that there are no other nearby cars on the crossing road or if the risk is small and the driver is running late for an important engagement. These are factors that do not enter into the traffic rule that one should stop at stop signs even though they are relevant to a social evaluation of best driving behavior at an intersection. When one considers the importance of such circumstantial information in the domain of traffic rules, one comes to the judgment that the occasions in which violating a rule would be socially desirable will be far from rare.

2.2.3. Tax Codes. Individuals face an array of legal obligations to pay taxes, including income taxes, sales taxes, and gasoline and other taxes on specific goods and services. I think it likely that many individuals believe that paying these taxes is broadly socially desirable because of the social harms that would be engendered were the state not to collect them. They believe this, I suggest, essentially due to inferences from the fact that the tax laws have been enacted. They know that the tax laws are designed by the state and reflect many factors about which most individuals are unlikely to have more than a vague understanding, including the cost and value of government activities, the impact of income taxes on incentives to work and invest, the influence of taxes on the volume of goods sold, and the effect of taxes on the distribution of wealth. Because of individuals' lack of knowledge about these factors and their complexity, my conjecture is that many individuals view the observed tax system as embodying a significantly better judgment about the socially desirable tax system than the one that they themselves could independently formulate. ${ }^{34}$

34. Notwithstanding this conjecture, which probably applies to a majority of citizens, there are many individuals who believe that the tax laws are socially undesirable, notably, those individuals who think that society should not impose income taxes, or only minimal income taxes, on libertarian grounds. 
Nevertheless, it also seems plausible that these individuals who believe that the tax laws are socially desirable to obey on the whole will sometimes find that their circumstances and personal knowledge suggest that disobeying the tax laws would be socially good. Consider whether paying a new and higher gasoline tax whose main purpose is announced to be to lower the consumption of gasoline would be socially desirable for a person who has already reduced his amount of driving to a minimal level and who has a strong need for funds in order to pay for medical care. This person could be imagined to reason that since the main purpose of the new gasoline tax is to discourage consumption of gasoline and that that object would not be achieved in his particular case, it would be socially good for him to evade the tax (perhaps by making an off-the-books purchase) and instead spend the new tax amount on his medical needs. In other words, it is not difficult to envision circumstances in which a person who generally endorses the social desirability of the tax system would decide that violating the tax laws would be socially good in that person's particular circumstances.

2.2.4. Shoplifting Laws. Stealing items from stores while shopping, that is, shoplifting, is a violation of the law. I presume that most individuals believe that shoplifting is socially undesirable because they know that shoplifting is a form of theft, which they would generally regard as socially undesirable. That shoplifting is an illegal act would therefore not seem to be important to their views about its undesirability; they would hold their views in any case.

Even though I suppose that individuals believe that shoplifting is generally socially bad, circumstantial information could lead an individual to conclude that shoplifting would be socially desirable. Suppose that a person knows that the closing time of a variety store is 6 P.M. and that immediately after closing, the store manager will remove the baked goods from their container on the counter and discard them. A few minutes before closing, when no one else is in the store, the person contemplates stealing a doughnut from the container. This act would cause no harm, by assumption, whereas it could benefit the person, and especially so if he is penniless and hungry. Hence, the person might believe that the act of shoplifting would be socially desirable. Such situations seem unusual relative to situations in which noncompliance with fire safety or traffic rules would be desirable, but they are not difficult to envision. 
2.2.5. Murder. The intended killing of a human being is classified as the crime of murder (subject to standard exceptions). ${ }^{35}$ I assume that individuals regard murder as socially undesirable and would view it this way regardless of whether it were a crime. Still, as with shoplifting, one can imagine situations in which a person might consider a murder to be socially desirable, for example, certain mercy killings or, say, the slaying of an active murderer who would otherwise escape capture. ${ }^{36}$

\subsection{Comments on the Model}

\subsubsection{The Tendency of Individuals to Believe That Compliance with the Law} Is Best and the Importance of Rational Inference from the Legal Status of Acts. I have suggested in the analysis that individuals should often come to the belief that compliance with the law is socially desirable and that a reason for that belief is the rational inference that individuals draw about the harmfulness of acts that are classified as unlawful. Further, it seems to me that in reality, the role of inference will frequently be important, as the discussion of the examples concerning fire safety regulation, traffic rules, and the tax laws I hope helps to show. More generally, these examples are intended to illustrate that in the modern, complex world, the design of the law frequently involves governmental evaluation of specialized knowledge, and that because individuals understand this to be so, it is valuable for them to know whether acts are legally proscribed or legally permitted.

At the same time, there exist many legally impermissible acts that individuals would usually view as socially undesirable from their direct knowledge of the acts, that is, regardless of the legal status of the acts. The examples of shoplifting and murder illustrate such acts, as does storing gasoline near a furnace and other patently negligent acts.

The distinction between illegal acts that individuals believe to be undesirable due to inference from their illegal status and those illegal acts that they believe to be undesirable from their direct knowledge reflects the point that the fact that an act would be a violation of the law carries no weight per se for an individual's evaluation of whether

35. Notably, self-defense or necessity may justify a killing.

36. The main character in a popular Showtime TV program, Dexter, kills active murderers whom the police are unlikely to be able to convict. Dexter has an advantage in identifying such murderers because he is an employee of the Miami Metro Police Department and has access to its databases on crime. See HBO, Dexter (http://www.sho.com/site/ dexter/home.do). 
the act would be socially undesirable to commit. When individuals decide that not committing an act is best because they learn that the act is illegal, the only reason that their knowledge of the illegality of the act affects their views is their inference about the harmfulness of the act. If they already have complete knowledge of the harmfulness of an act (if the distribution of $H_{\mathrm{S}}$ is concentrated at a single point), its legal status will not influence their opinion about its social desirability.

2.3.2. Inference from Sanctions and Their Probability of Application. In the analysis, the inference of individuals from the law about the harmfulness of acts was based only on their legal status, impermissible or permissible. More generally, however, individuals can make further inferences about impermissible acts from the magnitude of sanctions for committing them and from the likelihood of the imposition of sanctions, for these factors can convey significant information about the harmfulness of violations. ${ }^{37}$ For example, if a safety regulation forbidding use of certain types of furnaces stipulates high penalties for its violation and is rigorously enforced, individuals would infer that these furnaces are quite dangerous.

\subsubsection{Importance of the Possibility That Individuals Will Believe That Dis-} obeying the Law Is Socially Desirable. I have also discussed in the analysis that individuals may conclude that disobeying the law would be socially desirable and that such possibilities arise because legal rules omit circumstantial factors of which individuals are aware and which are relevant to social welfare. From this perspective, it is not surprising that there are many areas of law, such as those governing driving behavior and fire safety, in which individuals would fairly frequently, or at least not unusually, decide that noncompliance would be socially good. If the reader considers legal rules more or less at random-say, disclosure obligations of companies or rules controlling the behavior of police and prosecutors or pollution regulations-I believe that he or she will come

37. To amplify, suppose that lawmakers in the model employ a known policy to determine not only which acts to make illegal but also the magnitude and probability of sanctions. (A social-welfare-maximizing policy would tend to result in higher sanctions and higher probabilities of their imposition the greater the harmfulness of impermissible acts.) Then, from observing the magnitude and probability of sanctions, individuals can make more refined inferences about the harmfulness of impermissible acts than they can in the version of the model studied in the analysis. 
to the view that the probability that a person would decide that noncompliance is socially desirable is not small. ${ }^{38}$ Hence, I suggest that the opinion that readers should hold is that situations in which disobeying the law would be socially desirable are far from anomalous and, thus, that the examination of such situations should have a real place on the agenda of analysts of the law.

2.3.4. The Social Contract and the Obligation to Comply with the Law. The foregoing conclusion from the analysis that disobeying the law may well be socially desirable appears to conflict with individual obligations under a social contract. For under the basic notion of a social contract, it is commonly supposed that individuals in an original position would agree to obey the law in order to secure the benefits of a well-ordered society. ${ }^{39}$ However, if individuals in an original position were considering a social contract, they would not agree to obey a legal rule under all circumstances if the rule were not perfectly designed. If they were discussing whether definitely to obey a rule to stop at a red light, they would not promise always to do that. They would not want to be bound to halt at a red light if they were in a hurry and there were no danger from going through the light. Were they to consent to stop at red lights in such circumstances, their social contract would have the irrational feature that it would sometimes make individuals worse off without making anyone else better off. Instead, their contract would permit certain disobedience to a rule requiring drivers to stop at red lights. The only kind of legal system that individuals in an original position would agree to obey unqualifiedly is a completely detailed legal system, one that incor-

38. To illustrate, a requirement that a company disclose materially unfavorable facts about the business prospects of a division that it is selling to a potential buyer might well not be socially desirable to obey: suppose that the seller knows that disclosure of such facts would not change the buyer's decision to acquire the division or the use to which it would be put, but disclosure would reduce the buyer's offer price by enough to prevent the seller from making a subsequent acquisition that would be socially valuable. Likewise, a rule limiting police searches to situations when police have probable cause might easily be envisioned to be socially desirable to disobey: suppose that a police officer has good reason to believe that a suspect is guilty of a crime, so that search is in fact socially justifiable, even though the officer could not prove the validity of this reason to a court. Similarly, a rule mandating that a firm not discharge a pollutant might often be socially good to violate: suppose that under the circumstances faced by the firm the cost of preventing the discharge would exceed the harm from releasing the pollutant.

39. See note 9 . 
porated all socially relevant variables. ${ }^{40}$ Yet such a legal system is a counterfactual one, for the practical reality is that, as I assumed in the model, the state cannot incorporate into the law many factors relevant to social welfare. Hence, I consider the social contractarian view to imply that individuals would agree to obey imperfect legal rules only when that would advance social welfare, and this view thus is consistent with the analysis here.

\subsubsection{The Obligation to Comply with the Law and the View of Government} as Having Superior Ability to Frame Legal Rules-the Thesis of Raz. The analysis of this section also bears on the thesis of a leading present-day commentator on obedience to the law, Joseph Raz (see Raz 1986, chap. 3; and on Raz's work, see, for example, Shapiro 2002, pp. 402-415; Southern California Law Review 1989). The central argument that Raz advances is that individuals should comply with the law under a general assumption, the essence of which is that individuals will promote a stipulated goal better if they follow the law than if they attempt to foster that goal themselves. ${ }^{42}$ If this assumption holds, Raz reasons that individuals should surrender their decision-making autonomy to lawmakers-they should allow their personal beliefs to be "preempted" by lawmakers-and should obey the law. ${ }^{43}$ Moreover, Raz mentions that if individuals cede their decision-making autonomy to lawmakers, they will save themselves decision-making effort by not having to engage in caseby-case consideration of the desirability of compliance with the law (Raz 1986, pp. 58, 61-62).

My comments on the argument of Raz are twofold. First, I certainly agree that his argument is valid. Indeed, it appears to be a tautology. If an individual believes that another party-here a lawmaker-will better serve a goal that he endorses than he himself can, then of course the

40. Suppose, incredibly, that traffic lights were controlled by sensors that could perfectly monitor traffic conditions and the values that drivers placed on their time. Then if a driver approached an intersection when there was no traffic and the driver was late for an important engagement, the sensor would turn the light green; the light would be red only when on balance stopping was best. Individuals in the original position would agree always to obey red lights were this their nature.

42. On this assumption, see in particular $\operatorname{Raz}(1986$, p. 53), where he describes the normal justification of authority.

43. This is my distillation of the premise and the conclusion of the argument he made in Raz (1986, chap. 3, esp. at pp. 53, 57, 67-69); because his argument is lengthy, and in some respects elusive, others may summarize it differently. I also note that his argument about preemption seems to be in tension with his earlier writing (reprinted as Raz 1999, pp. 164-69). 
individual would rationally elect to grant decision-making power to that party.

But, second, the assumption on which Raz's argument is predicated does not hold with regard to the goal of promoting the social good. For realism demands that one take into account that individuals possess superior information to lawmakers about many variables of relevance to the social good-the variables that I have labeled circumstantial. Thus, as I have explained at length, it is not true that the social good will generally be furthered if individuals follow the law. Hence, in order to know whether compliance with the law is best, individuals must engage in decision making themselves. They must combine in the manner that I have elaborated their own information about circumstantial variables with other information, including their inferential information reflecting the better knowledge of lawmakers about an additional set of variables. ${ }^{44}$

\subsubsection{Can the Law Be Relaxed When Circumstances Lead Individuals to Be-} lieve That Noncompliance Is Socially Desirable? The possibility that an individual would determine that noncompliance with the law would be socially advantageous in light of the circumstances raises the question of whether the law could somehow be relaxed in light of them. If that were so, an individual would socially usefully be led not to comply, or the law might not deem the behavior to be noncompliance under the circumstances.

Unfortunately, when the reason that the law does not reflect the circumstances is that courts cannot verify their occurrence, the answer to this question is no-the law cannot be relaxed owing to the circumstances. Suppose that it is practically impossible for courts to ascertain what the wind conditions were when a person applied a pesticide or what the traffic conditions were when a person went through a stop sign. ${ }^{45}$ Then the law cannot depend on these circumstances, for if it did,

44. Recall that the rational individual must compare $B$ to $H_{\mathrm{C}}+E\left(H_{\mathrm{S}}^{+}\right)$in order to ascertain whether compliance would enhance social welfare. Of significance is that the individual must often engage in real ratiocination to ascertain $E\left(H_{\mathrm{s}}^{+}\right)$, the expected harm that the lawmakers must have forecast given that they classified the act as impermissible. One should also bear in mind that there is a very different consideration that the rational individual must take into account in determining whether compliance would raise social welfare, namely, the compliance externality. This issue, the effect of the witnessing of compliance behavior on the compliance of observers, is addressed in the next section.

45. Note that the court may not know these conditions even though it does know that a violation occurred. Suppose, for example, that a witness observed a person applying a pesticide but did not note or remember the wind conditions at the time or that a police officer observed a driver going through a stop sign from a block away and thus was not able to see what the driver could, that there was no traffic coming on the intersecting road. 
any person could falsely claim that the circumstances justified his violation, and the law would be effectively vitiated. Hence, we can see that when courts cannot verify circumstances relevant to the social desirability of an illegal act, society finds itself in the position of having to enforce the law and sanction its violation even though society knows that some noncompliance is socially desirable. ${ }^{46}$

However, it is often true that courts can verify the occurrence of circumstances that are not incorporated into the law. In these contexts, there seems to be an opportunity to modify the law in light of the circumstances, and to some degree this actually occurs. To elaborate, a major reason that the law does not reflect various circumstances is that lawmakers find it impractical to articulate the law beyond a certain point; lawmakers' time is limited, and they can foresee and describe only so many particulars in statutes or in judicial opinions, even though these particulars can be verified by courts if they arise in a case. Consider a legal rule making use of a pesticide illegal and the circumstance that pesticide treatment is the only way of protecting a rare bonsai plant with high market value, or consider the code requirement that smoke alarms be placed in every bedroom and the circumstance I described in which a smoke alarm is already located in a hallway just outside a bedroom used as a study. We can well imagine that such circumstances would not have been mentioned in the law because of their specificity and unlikelihood. But these circumstances are quite plausibly verifiable by courts-a court should be able to ascertain whether a person owns a rare bonsai or whether he has a smoke alarm in the hallway outside a bedroom that is used as a study.

In such contexts, where lawmakers realize that it is impractical for them to provide explicitly in legal rules for many relevant specific circumstances whose occurrence can be verified by courts, lawmakers can employ standards. In particular, they can include standards allowing for otherwise applicable rules to be relaxed, where the standards supply principles that guide how the unnamed circumstances that may arise should be taken into account. For example, a standard might state that the rule normally barring the use of a pesticide would not apply if a

46. Indeed, it may even be true that we sometimes believe statements of violators who explain that their behavior was justified by the circumstances that applied. We may believe these violators because of the timbre of their voices and other signs of sincerity. In other words, even though the circumstantial factors that violators claim to justify their noncompliance are unverifiable for purposes of applying the law, some observers may be able to evaluate the truth value of the claims from behavioral cues of honesty. 
person could show that a hardship would be suffered without the pesticide or that the pesticide in fact presented little danger to third parties. To some extent, legal rules in fact display standards of this type. ${ }^{47}$ And to that extent, we might say that the law allows for noncompliance or, rather, that there is no noncompliance because the law itself recognizes the circumstances at issue.

\subsubsection{Should General Sanctions Be Reduced to Reflect the Possibility That} Circumstances May Lead Individuals to Believe That Noncompliance Is Socially Desirable? I said above that the law cannot be altered in light of circumstances when the circumstances cannot be verified by courts, such as when traffic conditions and a person's situation mean that going through a stop sign would be socially desirable. But even if the law cannot be relaxed in light of circumstances, the general magnitude of sanctions for violations can be set at relatively moderate levels so as not to discourage violations unduly-we would not want the penalty for going through a stop sign to be set so high that individuals would almost never go through a stop sign, regardless of their needs and regardless of the possibility that the dangers would be minimal. The socially desirable level of the sanction for a violation ought to reflect the likelihood that the circumstances would make a violation socially desirable and the social value of such a violation, as well as, of course, the complementary likelihood that a violation would be socially undesirable and the social harm that would then come about. In fact, the scale of sanctions for going through stop signs and many other violations is not draconian, and this scale, I suspect, can be explained in part by the observations just made.

\subsubsection{The Possibility That Individuals Will Believe That Legally Permitted} Acts Are Socially Undesirable. Although my main concern here has been with whether committing legally prohibited acts would or would not raise social welfare, I also mentioned that one could apply the analysis to the question of whether committing legally permitted acts would or would not raise welfare. I want to reiterate this point and suggest that it will not infrequently be true that individuals will find that engaging in permissible behavior would be socially undesirable. A person may not

47. Typical examples are 16 U.S.C.A. sec. 1539(a)(1)(B), which provides an exception to the prohibition against killing endangered species under the Endangered Species Act in cases of killings deemed incidental to otherwise lawful activities, and 11 U.S.C. sec. $523(\mathrm{a})(8)(\mathrm{B})$, which provides an exception to the rule making student loan debt undischargeable in cases of undue hardship. 
be required to yield at an intersection even though he realizes that doing so would be socially desirable because of an apparent danger; an individual might discover a loophole in the tax laws allowing a financial benefit that the individual realizes would be socially harmful to obtain; an individual might find that he could legally omit mention of negative information about a property he is selling but that doing so would socially undesirably mislead a buyer about its character; and so forth. Such examples are mirror images of the possibilities that failure to comply with the law might be desirable, and they also arise from the incompleteness of the law.

\section{THE COMPLIANCE EXTERNALITY AND SOCIAL WELFARE-THE EFFECT OF THE WITNESSING OF COMPLIANCE BEHAVIOR ON THE COMPLIANCE BEHAVIOR OF OBSERVERS}

As I stated in the introduction, to determine whether social welfare would be fostered by obeying the law, an individual should consider not only the effect of committing an unpermitted act itself on social welfare, as I examined in the preceding section, but also a compliance externality: the possibility that his compliance behavior would be observed by others and that their tendency to obey the law would then be altered. In discussing this compliance externality, I first ask whether an individual's compliance behavior would be witnessed by others and then proceed to inquire why witnessed compliance behavior might alter an observer's tendency to adhere to the law.

\subsection{Whether Compliance Behavior Is Observed by Others}

Clearly if individuals do not observe a person's compliance behavior, that behavior cannot affect their tendency to comply with the law. This point has importance because in many situations compliance behavior will not be noticed by others. If a person falsely claims a charitable deduction from his taxable income, no one may know about that, and likewise if a driver speeds late at night in a deserted area or if a contractor uses substandard materials in renovating a home.

Indeed, individuals who disobey the law have a motive to conceal their behavior from observers, as that lowers the likelihood that they would be legally sanctioned or face social disapproval for their violations. If a person does not discuss his illicit charitable deduction with others, the probability of a tax audit or of admonition by colleagues will be lower than it would be otherwise. 
Nevertheless, a person's failure to comply with the law will frequently be observed. This will be so, for instance, if a person disobeys traffic rules in plain sight of other drivers or if a person instructs employees at his restaurant to violate safety standards by serving food that is not fresh. Moreover, even if a person's noncompliance is not observed at the time that it occurs, evidence of that behavior may still be noticed later. If someone litters in a park when no one would see him do that, presumably the litter will remain as an indication of his noncompliance. Thus, when I say that compliance behavior is observed or witnessed by other individuals, readers should interpret this statement in the broad sense that these individuals may come to have knowledge of compliance behavior even if they do not literally see it when it occurs.

\subsection{The Effect of Witnessed Compliance Behavior on the Tendency of Observers to Comply with the Law}

Assuming now that the compliance behavior of a person will be noticed by others, I will examine how the compliance behavior of the observers would be altered. To do this, I will consider the effects of witnessed compliance behavior on what I take here to be the three major determinants of compliance behavior of observers. One is the desire to do social good; to the degree that a person wishes to raise social welfare (that his utility would be raised by so doing), the person will want to comply with the law (when that would be expected to augment social welfare). The second determinant of compliance behavior is the suffering of legal sanctions for noncompliance, and the third determinant is the experiencing of social sanctions for noncompliance. If we seek to ascertain how the witnessing of compliance behavior influences the future compliance behavior of observers, we must ask how the witnessing of compliance behavior could affect each of these determinants of compliance behavior. ${ }^{48}$

\subsubsection{The Effect of Observed Compliance Behavior on Observers' Desire to} Do Social Good-the Morally Tutelary Effect. Here I am referring to the assumption that observing compliance behavior may alter a person's desire to do social good and thus the person's motive to obey the law when that would promote the social good. In other words, the assump-

48. The three determinants of compliance behavior that I consider could be amplified. See, for example, Kahan (1997, pp. 352-61), for a wide-ranging discussion of channels of social influence on compliance with the law. 
tion is that if an observer sees that another individual has sacrificed his usual self-interest for the social good-for instance, learns that a colleague has paid income taxes out of a sense of civic duty-the observer may be led to increase the importance (perhaps only temporarily) that he attaches to the social $\operatorname{good}^{49}$ and consequently to obeying the law. Conversely, if an observer sees that another individual has violated the law even though that individual understands that noncompliance lowers social welfare-say, a driver is witnessed speeding or going through a stop sign even though the driver realizes that his act presents a substantial risk of an accident-the assumption is that the observer may then accord less importance to fostering the social good and to adherence to legal rules.

For the foregoing morally tutelary effect to occur, it is apparent that the observer must know that a person's witnessed compliance with the law was motivated by a desire to advance the social good rather than by the fear of sanctions for noncompliance (such as penalties for driving too fast or for tax evasion) or that a person's violation of the law occurred when the person understood that noncompliance would be socially undesirable. Thus, the observer of compliance behavior must know more than that the law was or was not obeyed for the witnessed behavior to exert a morally tutelary influence.

\subsubsection{The Effect of Observed Compliance Behavior on Legal Sanctions Ex-}

pected by Observers. An observer of compliance behavior can sometimes draw an inference about expected legal sanctions for noncompliance. For example, an observer might decide that the probability of detection of violation of a rule against discharging a pollutant into a river is low if the observer discovers that a firm that has knowledge of enforcement practices impermissibly discharges the pollutant into the river or might decide that the probability is high if the observer learns that such a firm does not discharge the pollutant into the river.

For such inference about expected legal sanctions to occur, observers must again know more than that the law was or was not violated. Notably, they must have reason to believe that those whose compliance behavior they witness have superior knowledge of expected sanctions. If a firm that illegally discharges a pollutant into a river knows less about

49. For this increase in importance to occur, it seems that the observer must have an attenuated desire to advance the social good and that the significance of the desire must be reinforced and the observer's level of awareness of it raised by the witnessing of behavior motivated by the social good. 
enforcement policy than an observer does, the observer would not be able to make an inference of much value about legal sanctions from the firm's compliance behavior. Observers must also often have knowledge about other factors that motivate compliance behavior in order to draw helpful inferences about expected legal sanctions. Suppose that a firm that discharges a pollutant into the river might have done so because proper disposal of the pollutant would have been unusually costly. Then observers would not necessarily be able to infer from witnessed noncompliance that enforcement was weak, even if the polluting firm was more knowledgeable about enforcement practices than the observer was.

The potential importance of inference about legal sanctions depends on the degree of uncertainty that observers initially have about their probability and magnitude. Observers will often face substantial uncertainty about sanctions, especially about their probability, in which case there will be real scope for observers to learn from the compliance behavior of others. Where observers already have good knowledge of the likelihood and magnitude of sanctions, however, witnessed compliance behavior can have little influence on their expectations of sanctions and, thus, on their tendency to adhere to the law.

Let me add that the observation of compliance behavior can affect expected sanctions through a route different from inference. Suppose that an observer sees that many drivers are speeding on an expressway. The observer might then figure that the likelihood that he would be sanctioned for speeding if he too decided to speed would be low, for the odds that the police would stop him rather than one of the many other speeders would be reduced. In other words, if police or other enforcement resources are limited, then observation of noncompliance might directly lower the probability of sanctions for noncompliance at that time.

\subsubsection{The Effect of Observed Compliance Behavior on Social Sanctions Ex-} pected by Observers. By social sanctions for noncompliance with the law, I mean expressions of disapproval, such as admonishing a person who is seen littering in a park or dissociating oneself from a person who one learns has cheated on his tax return. I assume that the inclination of an individual to impose such social sanctions is correlated with the importance that the individual accords to acting morally himself; that is, I assume that a person who attaches significant weight to behaving socially appropriately himself is more likely to want to express disapproval of 
another's misbehavior than a person who does not accord importance himself to advancing the social good. Under this assumption, an individual would predict that the likelihood of social sanctions would be greater the higher is the fraction of individuals in the population who place importance on advancing the social good.

It follows that the social sanctions that observers would expect to experience can be influenced by the compliance behavior that they witness. In particular, observers will sometimes be able to make judgments about the moral character of those whose compliance behavior they have seen, and when that is so, their assessment of the population proportion of those who do and do not place value on advancing the social good will change. Suppose that a person who learns that an individual has cheated on his income tax return knows that the individual has no special need for money; the individual cheated because of simple greed and the opportunity to evade taxes. The observer would then increase his estimate of the proportion of individuals in the population who have little desire to act morally and thus who are themselves less likely to impose social sanctions for disobeying the law.

This effect of observation of compliance behavior on expected social sanctions is of potential significance to the extent that observers are uncertain about the likelihood and magnitude of social sanctions. The less they know about expected social sanctions, the more that their observation of compliance behavior will influence their prediction of social sanctions; the more settled their beliefs about the likelihood and character of social sanctions, the less that their observation of compliance behavior can matter to expected social sanctions.

It should also be noted that any effect of compliance behavior on expected social sanctions will be general in nature in that it should be relevant to social sanctions for violation of any law, not just the particular law for which compliance behavior is observed. The reason is that if an observer believes that social sanctions are less likely because his estimate of the fraction of individuals in the population with little moral character has increased, he would predict that the likelihood of social sanctions would fall no matter which law were violated. This general influence is in contrast to the effect of witnessed compliance behavior on expected legal sanctions. If an observer believes that legal sanctions for tax cheating are less likely because he has witnessed tax evasion by a person who has real knowledge of tax enforcement policy, 
that will have no necessary implication for the observer's view of the legal sanction for violations of other laws.

\subsubsection{Implications of the Foregoing for a Person Evaluating the Effect of} Compliance Behavior on Observers. I have emphasized above that the effect of witnessed compliance behavior on observers depends significantly on the information that observers have about the circumstances surrounding the compliance behavior. It follows that for an individual to gauge the effect of the witnessing of his compliance behavior on observers, he has to take into account what observers are likely to know about his circumstances. This is an important consideration because observers' knowledge of his actual circumstances will vary according to the context. As I suggested in the introduction, if a driver considers speeding because of a medical emergency, he will need to take into account that other drivers might be unlikely to know about his urgent need and, hence, that their incentive to comply with the law might be reduced by witnessing his speeding. In contrast, a passenger in his car would know about his emergency, so that this person's incentive to comply with the law would not be undesirably lowered by observing his speeding.

\subsection{Summary Evaluation of the Compliance Externality}

We can now complete the answer to the question that we are addressing in this section, namely, how an individual can assess the effect on social welfare of his compliance behavior through its influence on the compliance behavior of others. This evaluation requires the individual to make two judgments. First, the individual must predict whether his behavior will be observed by others, as was discussed in Section 3.1, a task that seems straightforward. Second, the individual must assess how his behavior that is witnessed would be likely to affect the compliance behavior of observers, for the set of reasons just discussed in Section 3.2. Combining these two forecasts-multiplying the likelihood of observation of his behavior by its effect if seen-allows the individual to determine the expected effect of his compliance behavior on the compliance behavior of others and, hence, the influence of the compliance externality on social welfare.

When one reflects on the determinants of the compliance externality, I believe that he or she will come away with a somewhat qualified evaluation of its significance. As I have noted, noncompliance is not always noticed, especially because the motivation of parties who violate 
the law is not to be witnessed doing so. And if noncompliance is observed, the primary channels of influence on observers seem to lie in the three that I discussed, and their importance will often be circumscribed. More generally, the view taken here-that the effects of noncompliance on observers must be explicitly ascribed to particular channels of influence on their incentives and on their information-contrasts with the conventional view that the witnessing of noncompliance leads in some almost automatic manner to a greater likelihood of noncompliance by observers.

\section{COMPLIANCE BEHAVIOR IN LIGHT OF THE ANALYSIS}

\subsection{Compliance Behavior under the Assumption That Individuals Derive Utility from Social Welfare-That Is, Feel a Moral Obligation to Advance Social Welfare}

The analysis in the preceding two sections tells us how an individual can determine whether compliance with the law would raise social welfare. Therefore, the analysis should help to explain compliance behavior under the assumption that individuals derive utility from augmenting social welfare as well as from conventional sources of utility. The psychological interpretation of this assumption is that associated with moral obligation: if an individual acts in ways that we would describe as fostering social welfare, the individual will feel virtue and might experience praise; and if an individual fails to act so as to raise social welfare, the individual will suffer guilt and might be subjected to chastisement. ${ }^{50}$

Supposing that individuals have a desire to increase social welfare, we would predict that when individuals believe that compliance is socially desirable, they will comply with the law more often than we would expect solely from their fear of legal sanctions for noncompliance. Is it true in such circumstances that individuals comply with the law more often than they would merely to avoid legal sanctions? It is a commonplace that the answer is yes. It is patent that individuals pay their taxes, exercise care in their activities, refrain from criminality, and so forth much more often than they would if their only reason for obedience to the law were the threat of sanctions for its violation.

Second, we would predict that when individuals believe that compliance with the law is not socially desirable, they will obey the law less

50. Closely related views about the connection between individual utility and moral obligation are discussed by Kaplow and Shavell (2004, p. 21). 
often than would be expected from their fear of legal sanctions for disobedience. Is this the case? My surmise is that it is. Supporting this view is that individuals sometimes excuse noncompliance by appeal to considerations of social welfare, such as when they say that noncompliance will do little or no harm to others.

The analysis in Sections 2 and 3 also has normative implications for individuals who wish to advance social welfare. If such individuals endeavor to behave according to the analysis, meaning among other things that they may come to understand that they should sometimes feel no moral obligation to comply with the law (or, more exactly, a moral obligation to disobey the law), social welfare will be advanced on average.

\subsection{Compliance Behavior and the Possibility That Individuals Derive Utility from Obeying the Law per se-That Is, Feel a Moral Obligation to Obey the Law Regardless of Its Effect on Social Welfare}

Compliance behavior seems in fact to reflect not only a desire to raise social welfare but also a moral duty to obey the law per se, that is, a duty to obey that exists independently of the influence of compliance on social welfare.

To test this claim, we can ask ourselves whether individuals would be likely to feel guilt even if they violated the law when they realized that their violations would not lower social welfare. My suspicion is that in such situations, such as going through a red light when this would create no real risk, individuals do experience a measure of guilt. This guilt would not be suffered if the obligation to obey the law per se did not have moral valence. I have confirmed this conjecture in a pilot survey of moral attitudes about obeying traffic rules, ${ }^{51}$ and supportive general

51. The survey involved 46 individuals. The questions asked and the responses included these: (1) "Do you feel a moral obligation to stop at stop signs?" Of those who responded, 39 (89 percent) said yes and 5 (13 percent) said no. (2) "Would you feel a moral obligation to stop at a stop sign when there is truly no danger (assume that you can see that there's absolutely no traffic)?" Of those who responded, 30 (65 percent) said yes and 16 (35 percent) said no. (3) "Suppose that you go through a stop sign when there's truly no danger and you're in a hurry. Would you feel guilty?" Of those who responded, 24 (56 percent) said yes and 19 (44 percent) said no. The answers to these three questions, especially to the second and third, suggest that individuals feel a per se obligation to obey the law. Comparison of the answer to the first question with the answers to the second and third suggest that the moral obligation to obey stop signs is reduced in light of circumstances; whereas 89 percent say that they have a moral obligation to obey stop signs in general, only 65 percent say that they have such an obligation when there is no danger, and only 56 percent say that they would experience guilt from violating the law by going through stop signs. 
survey evidence also exists. ${ }^{52}$ The view that individuals have a desire to obey the law per se is also of a piece with the emerging scientific literature on morality and the emotions to which I referred earlier (see Haidt 2003; Hauser 2006, pp. 156, 220-21). The implication of individuals' placing value on obedience to the law in itself is, of course, that they will have a greater motive to obey than was discussed above, both when compliance is socially desirable and when compliance is socially undesirable.

\section{REFERENCES}

Alexander, Larry, and Emily Sherwin. 2001. The Rule of Rules: Morality, Rules, and the Dilemmas of Law. Durham, N.C.: Duke University Press.

Bentham, Jeremy. [1776] 1988. A Fragment on Government, edited by J. H. Burns and H. L. A. Hart. Cambridge: Cambridge University Press.

Darwin, Charles. [1874] 1998. The Descent of Man; and Selection in Relation to Sex. 2d ed. Amherst, N.Y.: Prometheus Books.

Edmundson, William A., ed. 1999. The Duty to Obey the Law. Lanham, Md.: Rowman and Littlefield.

$\rightarrow$ Elster, Jon. 1998. Emotions and Economic Theory. Journal of Economic Literature 36:47-74.

Frank, Robert H. 1988. Passions within Reason: The Strategic Role of the Emotions. New York: Norton.

Haidt, Jonathan. 2003. The Moral Emotions. Pp. 852-70 in Handbook of Affective Sciences, edited by Richard J. Davidson, Klaus R. Scherer, and H. Hill Goldsmith. Oxford: Oxford University Press.

$\rightarrow$ Hart, H. L. A. 1955. Are There Any Natural Rights? Philosophical Review 64: 175-91.

Hauser, Marc D. 2006. Moral Minds. New York: HarperCollins.

Hobbes, Thomas. [1651] 2008. Leviathan, edited by J. C. A. Gaskin. Oxford: Oxford University Press.

Hume, David. [1748] 1978. Of the Original Contract. Pp. 145-66 in Social Contract: Essays by Locke, Hume, and Rousseau. New York: Oxford University Press.

- . [1751] 1957. An Inquiry Concerning the Principles of Morals, edited by Charles W. Hendel. Indianapolis: Liberal Arts Press.

$\rightarrow$ Kahan, Dan M. 1997. Social Influence, Social Meaning, and Deterrence. Virginia Law Review 83:349-95.

52. See Tyler (2006, p. 46), whose survey results include the following: 85 percent of respondents agreed that "People should obey the law even if it goes against what they think is right," and 71 percent of respondents agreed that "It is difficult to break the law and keep one's self respect." 
Kaplow, Louis, and Steven Shavell. 2004. Fairness versus Welfare. Cambridge, Mass.: Harvard University Press.

$\rightarrow$ - 2007. Moral Rules, the Moral Sentiments, and Behavior: Toward a Theory of an Optimal Moral System. Journal of Political Economy 115:484514.

Locke, John. [1689] 1988. Two Treatises of Government, edited by Peter Laslett. $2 \mathrm{~d}$ ed. Cambridge, Mass.: Cambridge University Press.

$\rightarrow$ McAdams, Richard H. 1997. The Origin, Development, and Regulation of Norms. Michigan Law Review 96:338-433.

Pinker, Steven. 1997. How the Mind Works. New York: Norton.

Plato. 1997. Defence of Socrates, Euthyphro, and Crito, edited by David Gollop. Oxford: Oxford University Press.

$\rightarrow$ Posner, Eric. 1996. Law, Economics, and Inefficient Norms. University of Pennsylvania Law Review 144:1697-744.

$\rightarrow$ Posner, Richard A. 1997. Social Norms and the Law: An Economic Approach. American Economic Review 87:365-69.

$\rightarrow$ Rabin, Matthew. 1993. Incorporating Fairness into Game Theory and Economics. American Economic Review 83:1281-302.

Rawls, John. 1964. Legal Obligation and the Duty of Fair Play. In Law and Philosophy: A Symposium, edited by Sidney Hook. New York: New York University Press.

Raz, Joseph. 1979. The Obligation to Obey the Law. Pp. 233-49 in The Authority of Law: Essays on Law and Morality by Joseph Raz. New York: Oxford University Press.

- 1986. The Morality of Freedom. Oxford: Oxford University Press.

- 1999. The Obligation to Obey: Revision and Tradition. Pp. 159-76 in The Duty to Obey the Law: Selected Philosophical Readings, edited by William A. Edmundson. Lanham, Md.: Rowman and Littlefield.

Rousseau, Jean-Jacques. [1762] 1968. The Social Contract, trans. Maurice Cranston. London: Penguin Books.

Schauer, Frederick F. 1991. Playing by the Rules: A Philosophical Examination of Rule-Based Decision-Making in Law and in Life. Oxford: Oxford University Press.

Shapiro, Scott. 2002. Authority. Pp. 382-439 in The Oxford Handbook of Jurisprudence and Philosophy of Law, edited by Jules Coleman and Scott Shapiro. Oxford: Oxford University Press.

Shavell, Steven. 2002. Law versus Morality as Regulators of Conduct. American Law and Economics Review 4:227-57.

Simmons, A. John. 1979. Moral Principles and Political Obligations. Princeton, N.J.: Princeton University Press.

Smith, Adam. [1790] 1976. The Theory of Moral Sentiments. 2d ed. Oxford: Clarendon. 
Smith, M. B. E. 1973. Is There a Prima Facie Obligation to Obey the Law? Yale Law Journal 82:955-76.

- 2010. The Duty to Obey the Law. Pp. 457-66 in A Companion to Philosophy of Law and Legal Theory, edited by Dennis Patterson. 2d ed. Malden, Mass.: Wiley-Blackwell.

Southern California Law Review. 1989. Symposium: The Works of Joseph Raz. Special issue, 62:731-1152.

Tyler, Tom R. 2006. Why People Obey the Law. Princeton, N.J.: Princeton University Press. 